\title{
Innovative design of the world's tallest electrical transmission towers
}

Fei Xu

Post-doctoral Fellow, Institute of Structural Engineering, Zhejiang University,

Hangzhou, Zhejiang, China; Department of Civil and Environmental

Engineering, The Hong Kong Polytechnic University, Hong Kong, China

\section{Ju Chen}

Professor, Institute of Structural Engineering, Zhejiang University,

Hangzhou, Zhejiang, China (corresponding author: cecj@zju.edu.cn)

\section{Yong Guo}

Senior Engineer, Zhejiang Electric Power Design Institute Co., Ltd, Hangzhou, Zeijiang, China

Yin Ye

Senior Engineer, Zhejiang Electric Power Design Institute Co., Ltd, Hangzhou, Zhejiang, China

Providing a new $500 \mathrm{kV}$ electricity supply to Zhoushan Islands off the east coast of China in 2018 involved building the world's two tallest transmission towers. The $380 \mathrm{~m}$ typhoon-resistant towers enabled high-voltage cables to span $\mathbf{2 . 7} \mathbf{k m}$ over the East China Sea. To reduce wind loads, the towers were made from a tubular steel filled with steel angle-reinforced, self-compacting concrete. This paper describes the design and detailing of the innovative composite members and joints specifically developed for the project. It aims to serve as a design reference for future long-span electrical transmission towers.

\section{Notation}

$A_{\mathrm{c}} \quad$ cross-sectional area of concrete

$A_{\mathrm{si}} \quad$ cross-sectional area of built-up latticed angles

$A_{\text {si }} \quad$ cross-sectional area of steel tube

$C_{\mathrm{si}}^{\mathrm{so}} \quad$ total circumference of the encased angles

$D \quad$ tube diameter

$D_{\mathrm{b}} \quad$ tube diameter of the brace

$E_{\mathrm{c}} \quad$ elastic modulus of concrete

$E_{\mathrm{si}} \quad$ elastic modulus of steel tube

$E_{\text {so }} \quad$ elastic modulus of encased angle

$E A \quad$ initial stiffness of tensile member

$e \quad$ load eccentricity

$F_{\text {Builtup }}$ design compressive strength of latticed built-up angles

$F_{\text {CFST }}$ design compressive strength of the concrete-filled steel tube (CFST) member

$F_{\text {u,AXT }}$ punching shear design strength for the connection under axial tension

$F_{\text {u,ECT }}$ punching shear design strength for the connection under eccentric tension

$f_{\text {ck }} \quad$ characteristic compressive strength of concrete

$f_{\mathrm{u}}^{\text {ck }} \quad$ ultimate strength of steel

$f_{\text {ui }} \quad$ ultimate strength of steel angle

$f_{\text {uo }} \quad$ ultimate strength of steel tube

$f_{\mathrm{y}} \quad$ yield strength of steel

$f_{\mathrm{yi}} \quad$ yield strength of steel angle

$f_{\text {yo }} \quad$ yield strength of steel tube

$L \quad$ column length

$l_{\mathrm{b}} \quad$ gusset plate length

$M_{\mathrm{p}} \quad$ ultimate flexural strength of the cross-section of embedded components

$M_{\text {scu }} \quad$ ultimate flexural strength of the CFST member

$M_{u} \quad$ flexural strength of reinforced CFST members

$M_{\mathrm{u}, \mathrm{AXT}}$ flexural strength of reinforced CFST members under axial tension

$M_{\mathrm{u}, \mathrm{IB}}$ punching shear design strength for the connection under in-plane bending

$T \quad$ tube-wall thickness of the compressive and tensile members

$t \quad$ tube-wall thickness of the chord $t_{\mathrm{b}} \quad$ tube-wall thickness of the branch members

$\alpha_{\mathrm{T}} \quad$ steel ratio, $A_{\mathrm{so}} / A_{\mathrm{c}}$

$\beta \quad$ stress coefficient

$\beta_{\text {si }} \quad$ stress coefficient of the angle

$\beta_{\text {so }} \quad$ stress coefficient of the tube

$\gamma \quad$ flexural strength index

$\gamma_{\mathrm{m}} \quad$ flexural strength index according to Han (2006)

$\eta \quad$ stress coefficient

$\eta_{\mathrm{si}} \quad$ stress coefficient of encased angles

$\theta \quad$ brace angle

$\lambda \quad$ slenderness ratio

$\xi \quad$ confinement factor, $A_{\mathrm{so}} f_{\mathrm{yo}} / A_{\mathrm{c}} f_{\mathrm{ck}}$

$\rho_{\mathrm{si}} \quad$ reinforcement ratio, $A_{\mathrm{si}} f_{\mathrm{yi}} / A_{\mathrm{c}} f_{\mathrm{ck}}$

$\rho_{\text {si, } \mathrm{T}} \quad$ angle/tube ratio, $f_{\mathrm{yi}} A_{\mathrm{si}} \mid f_{\mathrm{yo}} A_{\mathrm{so}}$

$\phi_{\mathrm{si}} \quad$ angle property factor

$\chi \quad$ ratio of reinforcement ratio to confinement factor

$\omega \quad$ load eccentricity ratio of the CFST specimen, $2 e / D$

\section{Introduction}

A $500 \mathrm{kV}$ electrical transmission project between Zhoushan Islands and the city of Ningbo on the eastern China mainland was initiated in 2007 to solve the problem of electricity supply shortages on the islands. The two-stage project was approved by the government of Zhejiang Province and managed by Zhejiang Electric Power Corporation and Zhoushan Electric Power Bureau. Design was by Zhejiang Electric Power Design Institute Co., Ltd and construction was by Zhejiang Power Transmission and Transformation Corporation.

The first stage was for an overhead transmission line across the Luotou channel of the East China Sea between Damao and Liangmao Islands, a distance of $2750 \mathrm{~m}$ (Figure 1). This required the design and construction of two $370 \mathrm{~m}$ tall transmission towers, which until 2018 were the tallest in the world (Figure 2(a)). Completed in 2010, the total cost of the crossing was approximately US\$85 million.

The second stage was for a submarine transmission line from Ningbo to Jintang Island, which was then carried $2656 \mathrm{~m}$ over the Xihoumen channel to Cezi Island by means of two $380 \mathrm{~m}$ tall 


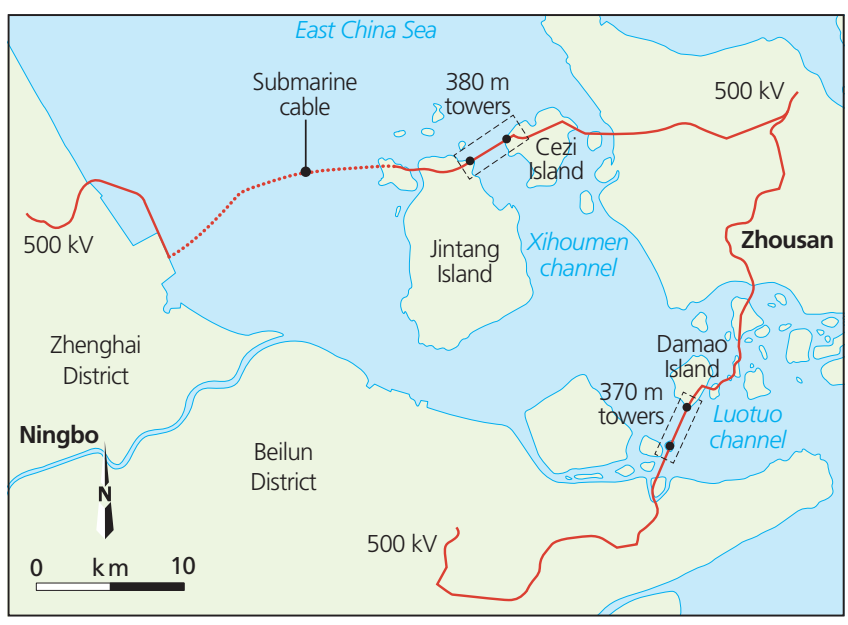

Figure 1. Plan of the $500 \mathrm{kV}$ Zhoushan-mainland electrical transmission lines

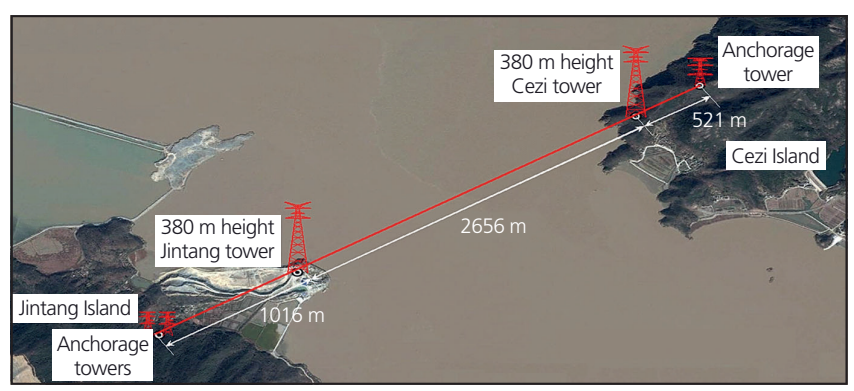

Figure 3. Schematic view of the Xihoumen cable crossing completed in 2018

towers (Figure 2(b)) and three smaller anchorage towers (Figure 3). Construction started in December 2016, the towers were completed in October 2018 and the line was commissioned in December 2018. The cost of the Xihoumen crossing was US\$91 million.

Like the earlier $370 \mathrm{~m}$ tall towers, concrete-filled tubular steelwork was adopted for the $380 \mathrm{~m}$ tall tower structures based on comprehensive consideration of external actions, manufacturing, construction and design codes. However, some challenging technical problems needed to be solved during design, manufacture and construction.

This paper introduces the key techniques adopted and the innovative structures proposed for the towers. The structural performance and the design methods are also presented. Close collaboration between the structural designers and university researchers was of great importance during the design and construction processes to overcome the challenges and achieve a successful completion.

\section{Structural selection}

The two towers are identical and located at Jintang and Cezi Islands, respectively. The steel weight of each tower is $7280 \mathrm{t}$, making them the heaviest transmission towers in the world. The four main columns were constructed up to a height of $262 \mathrm{~m}$ using

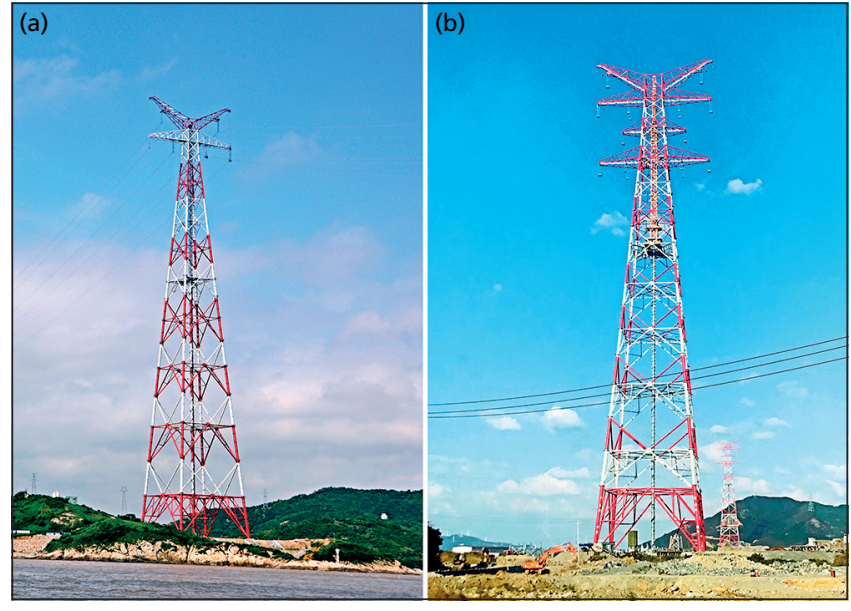

Figure 2. One of the $370 \mathrm{~m}$ tall electrical transmission towers completed in 2010 (a) and one of the $380 \mathrm{~m}$ tall versions completed in 2018 (b)

concrete-filled steel tubes (CFSTs) with encased reinforcement lattices made from steel angles.

The maximum diameter and tube-wall thickness of the column tubes is $2300 \mathrm{~mm}$ and $28 \mathrm{~mm}$, respectively. The tubes are made from Q345 steel (nominal yield strength of $345 \mathrm{MPa}$ ) and the $200 \mathrm{~mm} \times$ $200 \mathrm{~mm} \times 24$ thickness angles are made from Q420 steel.

A total of $3200 \mathrm{~m}^{3}$ C50 (28 d strength of $50 \mathrm{MPa}$ ) selfcompacting concrete fill was pumped into position in several lifts.

The towers are located in a typhoon-prone sea strait. The design wind speed was $41 \mathrm{~m} / \mathrm{s}$ based on a report by the Meteorological Bureau of Zhejiang Province. Huang et al. (2012) performed experimental and numerical investigations into wind effects on the towers.

The preferable structure profile was a circular hollow section (CHS) tubular structure, which has a lower wind-load shape coefficient compared with a steel angle lattice structure. According to the preliminary design, adopting CHS for the main columns would have required a maximum diameter of $2300 \mathrm{~mm}$ to meet the requirements of external actions.

Furthermore, the tube-wall thickness would have had to be at least $32 \mathrm{~mm}$ for Q345 steel according to the Chinese code for design of steel structures (SAC, 2003a), in which the ratio of diameter $(D)$ to thickness $(T)$ is limited to $100(235 / f$ ).

Eurocode 3 (BSI, 2005a) has a stricter limit for the sectional slenderness ratio $(D / T)$ than the Chinese code. The crossclassifications in Eurocode 3 (BSI, 2005a) for compressive members were catalogued as class 1, 2, 3 and 4, based on the cross-section's local buckling resistance. The $D / T$ limit values for tubular sections were defined as $50\left(235 / f_{\mathrm{y}}\right), 70\left(235 / f_{\mathrm{y}}\right)$ and $90\left(235 / f_{\mathrm{y}}\right)$ for class $1-3$ sections, respectively. Therefore, even if the cross-section had been designed as class 3, which may have used parts of plastic moment resistance due to local buckling; taking $D / T=80(235 / f$ ) for example, the tube-wall thicknesses would have been larger than $40 \mathrm{~mm}$ for Q345 steel and approximately $50 \mathrm{~mm}$ for Q420 steel. It should be noted that this was only for the consideration of local buckling. Furthermore, the relatively thick tube wall would have introduced problems in both manufacturing and construction processes. 
The design strength of thick steel plate was factored due to defects and manufacturing processes, which indicated that increasing the thickness of the tube walls might not be of much benefit to increase the ultimate capacity of members according to the Chinese code.

For instance, the design strengths for $32 \mathrm{~mm}$ and $35 \mathrm{~mm}$ thick steel plate (Q345) were $295 \mathrm{MPa}$ and $265 \mathrm{MPa}$, respectively, which indicated that if the tube thickness increased from $32 \mathrm{~mm}$ to $35 \mathrm{~mm}$, the compressive material strength $\left(f_{\mathrm{y}} A_{\mathrm{so}}\right)$ of a $2200 \mathrm{~mm}$ CHS would decrease from $64296 \mathrm{kN}$ to $63084 \mathrm{kN}$. Furthermore, increasing the tube-wall thickness would not be uneconomical but would also bring additional problems in structural performance.

In the Chinese code, steel with a yield strength $(f)$ larger than $345 \mathrm{MPa}$ and a ratio of yield strength to ultimate strength $\left(f_{\mathrm{y}} / f_{\mathrm{u}}\right)$ larger than $0 \cdot 8$ should not be used in hot-rolled and cold-formed tubular structures. In addition, tube-wall thickness was advised to be no more than $25 \mathrm{~mm}$ for considerations of machinability, formability and ductile recovery after working processes to prevent lamellar tearing during plate manufacturing. Alternatively, special processing techniques could have mitigated lamellar tearing but it would have increased costs by approximately $40 \%$.

For the tower columns designed using hollow sections, the tubewall thickness would have had to be more than $40 \mathrm{~mm}$ to meet the requirements of both strength and stability. From a manufacturing perspective, a special machine for plate-bending would have been necessary to achieve sufficient accuracy. Moreover, special attention would have been needed to ensure the welding quality at joints.

\subsection{Reinforced concrete infill solution}

CFSTs have been renowned for their superior mechanical performance and excellent constructional properties for more than half a century (Han, 2006; Han et al., 2014; Perea et al., 2013; Uy, 2001; Wang et al., 2018a, 2018b). They have been widely applied in building structures, bridges, power transmission towers and marine structures to utilise the advantages of both steel and concrete materials (Han et al., 2014).
Therefore, the feasibility of applying CFST structures in the Zhoushan transmission towers was investigated. After structural calculation and comprehensive considerations on the issues related to manufacturing and construction, it was decided to use a CFST structure for the towers. The severe local buckling in slender sections and lamellar tearing due to the thick tube wall could be avoided by using infill concrete. The concrete significantly decreased the required tube-wall thickness and improve local buckling resistance.

To overcome the problems with using hollow sections, an innovative CFST member with encased angle lattices was proposed and successfully applied up to a height of $262 \mathrm{~m}$ in the $380 \mathrm{~m}$ tall towers (Figure 4). The encased angle lattices provided an economical solution to the insufficient steel ratio for the largescale composite tubular structures, improved the composite effects between each component and thus increased the composite member strengths.

Furthermore, the reduced tube-wall thickness reduced the cost of cold-formed manufacturing and welding quality control. Meanwhile, the encased angle lattices could serve as inner scaffolding before casting concrete and therefore provide access for internal construction work. Due to the lack of design methodology in domestic and international design specifications, the mechanical performance of the proposed structure was extensively investigated to obtain the optimal design approaches (Chen et al., 2017a, 2017b; Xu et al., 2014, 2017c).

\subsection{Joint design}

Both gusset plate and CHS tube to CFST joints were adopted below $262 \mathrm{~m}$, while spherical steel joints were applied for the upper steel truss structure (Figure 5). The tube splice in members of the largest diameter $(2300 \mathrm{~mm})$ is shown in Figure 6.

Although the infill concrete did not directly contribute to the strength of the composite joint, it changed the chord stiffness and thus altered the failure modes. Conservatively adopting the design approaches for pure steel CHS joints would not only have led to
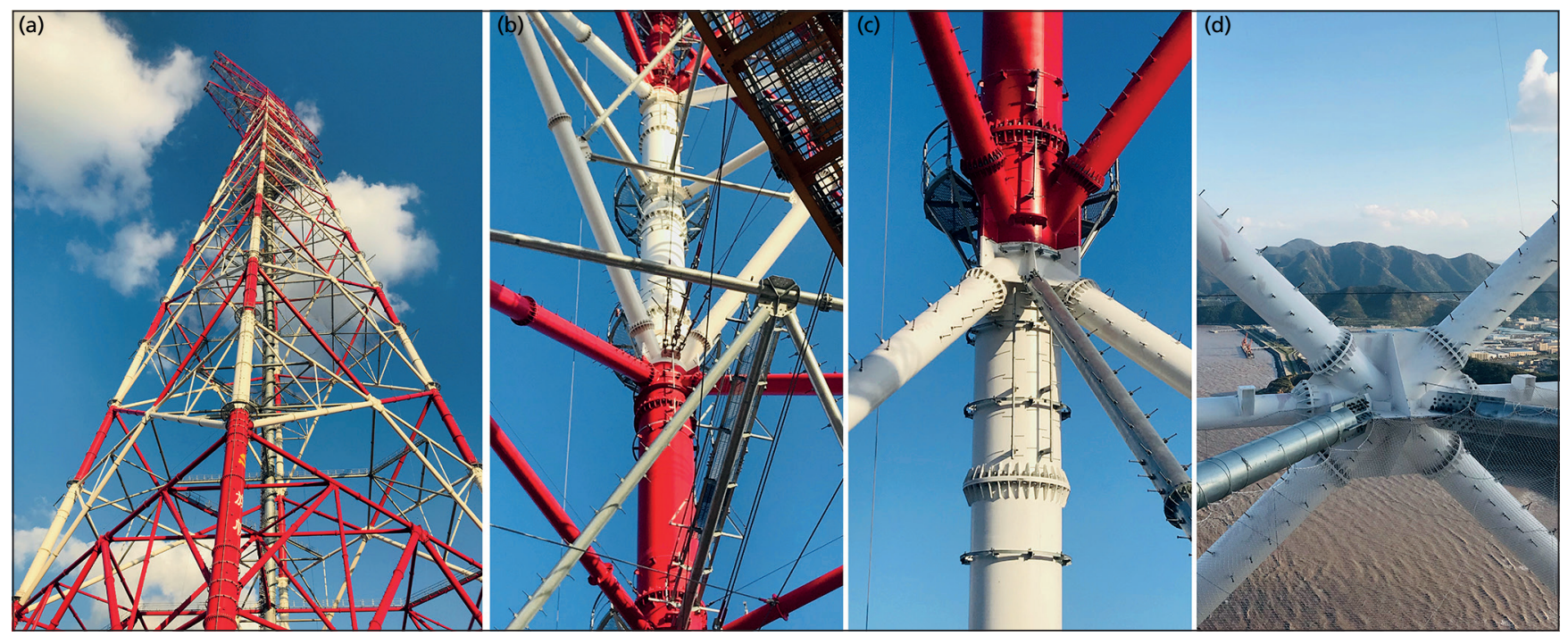

Figure 4. Structural members and connections of the $380 \mathrm{~m}$ tall transmission tower: (a) overview; (b) tubular joints; (c) detail of double $\mathrm{K}$ joint; (d) detail of spatial joints. Concrete infill is used up to $262 \mathrm{~m}$ 


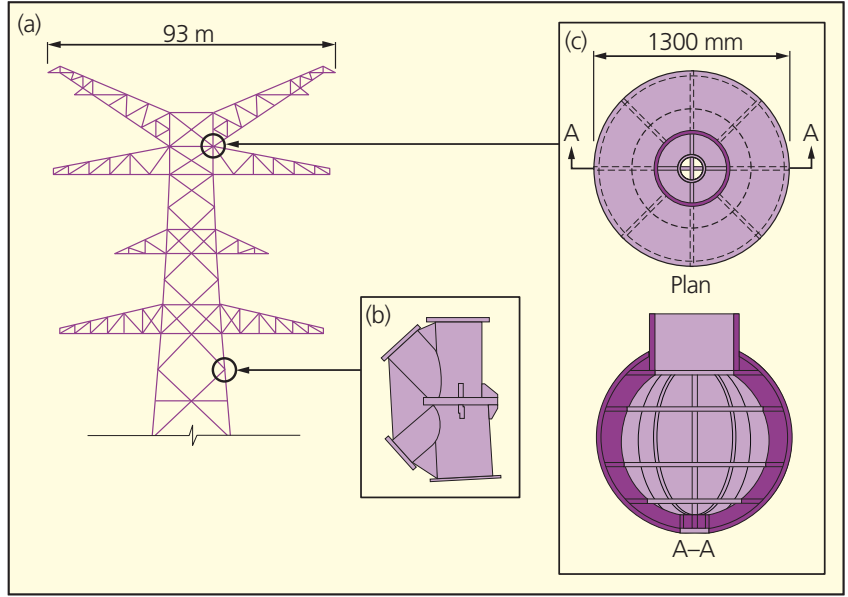

Figure 5. Diagram of upper non-concrete-filled section of tower (a), conventional joint design (b), spherical joint Q1 design (c)

an uneconomical design but may also have caused errors in the overall structural analysis. Therefore, extensive investigation on the mechanical performance of the composite joints under various loading conditions was conducted. A design framework was established for practical engineering (Chen et al., 2010; Xu et al., 2015a, 2016a, 2016b, 2017a, 2017b).

Near the top end of the columns, approximately $87 \mathrm{~m}$ in Figure 5 , a specially designed spherical joint was proposed to simplify the load-transfer mechanism from the branches to the main members (Figure 5(c)). The spherical joints reduced the possible initial eccentricity during manufacturing and installation. They could therefore achieve a better mechanical performance compared with a conventional welded-spatial CHS joint in Figure 5(b). The maximum diameter of the spherical joint was $2000 \mathrm{~mm}$.

According to the Chinese technical specification for latticed shells (SAC, 2003b), the thickness of a joint should have been $45-80 \mathrm{~mm}$, which could have brought great difficulties in manufacturing and construction. Therefore, inner stiffeners were adopted to improve the local buckling resistance of the shell and thus decrease the shell thickness to $24 \mathrm{~mm}$. The arrangement of inner stiffeners is as shown in Figure 5(c). The numerical analysis showed that the design method in the Chinese specification could provide a satisfactory prediction for the hollow section stiffened spherical joint.

\section{Structural investigations}

\subsection{CFSTs with angle lattice reinforcement}

The experimental (Chen et al., 2017a, 2017b; Xu et al., 2014) and numerical ( $\mathrm{Xu}$ et al., 2017c, 2019) investigations on the compressive and tensile performance of CFST columns with an encased built-up lattice were conducted. The test specimens were scaled to one of the main members in the transmission tower, as shown in Figures 7(a) and 7(b). A total of 35 CFST test specimens with encased built-up angle lattices and their counterparts as the control groups were tested under axial compression (Xu et al., 2014), axial tension (Chen et al., 2017a; Xu et al., 2019) and eccentric tension (Chen et al., 2017b).

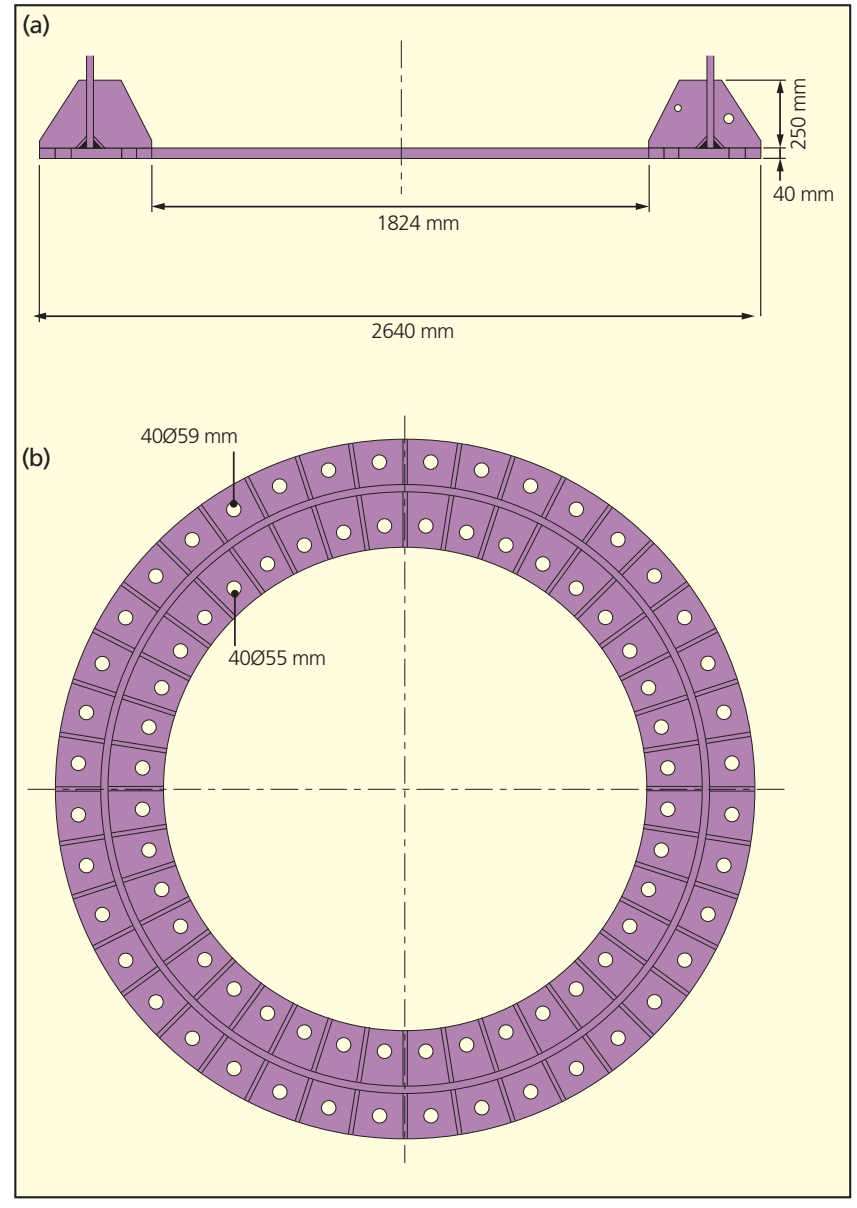

Figure 6. Flange splice for $2300 \mathrm{~mm}$ concrete-filled main members: cross-section (a) and plan (b)

The effects of built-up angle lattices on local buckling, global buckling and steel-concrete composite actions were experimentally investigated by 14 composite column specimens. The typical failure modes for specimens are shown in Figure 7(c). The discrepancy on the failure modes was found in the angle-reinforced specimen and its counterpart CFST (in $2500 \mathrm{~mm}$ length). The failure mode of the non-reinforced test specimen was shear failure of the inner concrete at the bottom, while the specimen with encased lattice angles failed at global buckling.

The inner angle lattice would effectively prevent the development of diagonal shear cracking in the concrete. The ultimate strength of each test specimen proved that the encased angle lattices could effectively enhance the compressive capacity and have little influence on the compressive stiffness and ductility. As shown in Figure 7(c), the angle lattices could work together with the surrounding concrete.

The design equations of the encased angle lattice CFST column are shown in Equations 1 to 3 (Xu et al., 2017c). The proposed design approach was able to provide a reasonable and reliable prediction, achieving a satisfactory balance between accuracy and safety. 
Civil Engineering

Volume 172 Issue CE5
Innovative design of the world's tallest electrical transmission towers

$\mathrm{Xu}$, Chen, Guo and Ye

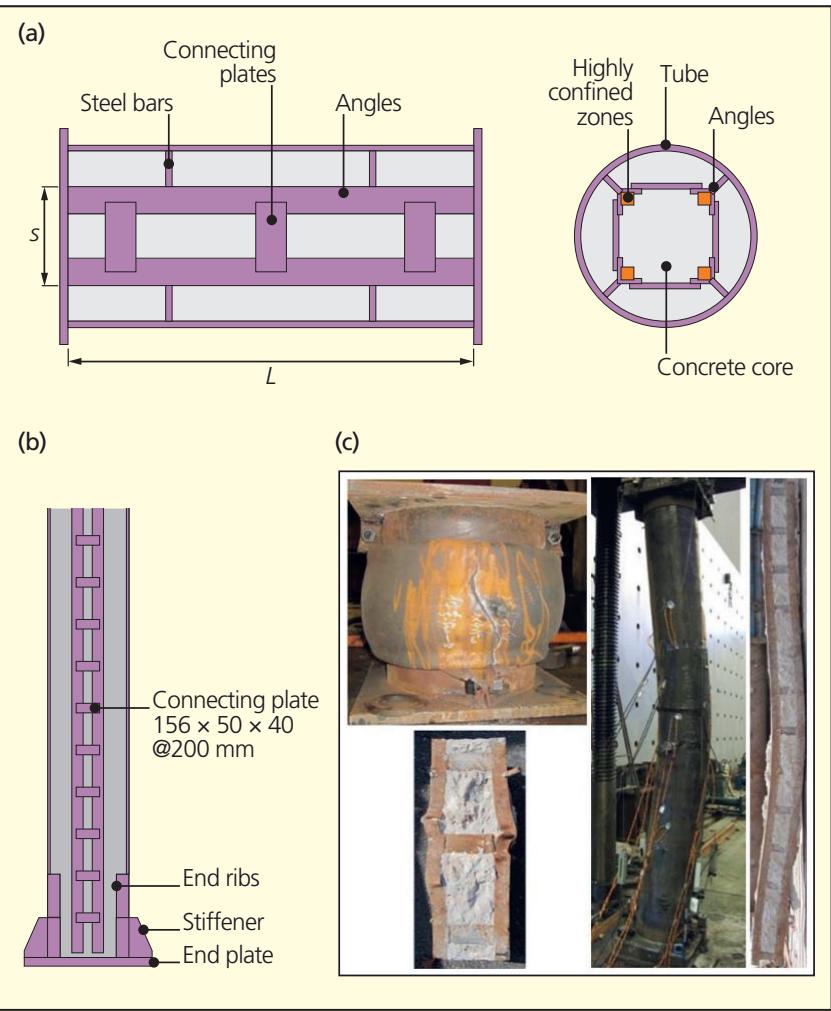

Figure 7. Test specimens of a CFST column with encased angle lattice (Chen et al., 2017a, 2017b; Xu et al., 2014, 2017c, 2019): (a) schematic view of compressive specimens; (b) schematic view of tensile specimens; (c) failure modes of compressive specimens

1. $\eta_{\mathrm{si}}=e^{-1 \cdot 425} \times \chi^{-1 \cdot 081}=0 \cdot 241 \chi^{-1 \cdot 081}$

when $\lambda \leq 20 \cdot 0$,

2. $F_{\mathrm{u}, \mathrm{AXT}}= \begin{cases}F_{\mathrm{CFST}}+\left(1+0 \cdot 241 \chi^{-1 \cdot 081}\right) F_{\text {Built-up }} & 0 \cdot 509<\chi \leq 2 \cdot 0 \\ F_{\mathrm{CFST}}+1 \cdot 5 F_{\text {Built-up }} & 0 \cdot 1 \leq \chi \leq 0 \cdot 509\end{cases}$

when $\lambda>20$,

3. $F_{\mathrm{u}, \mathrm{AXT}}=F_{\mathrm{CFST}}=F_{\text {Built-up }}$

where $F_{\text {CFST }}$ is the design compressive strength of the CFST member calculated from AISC (2010) and $F_{\text {Built-up }}$ is the design compressive strength of latticed built-up angles calculated using AISC (2010).

A total of 28 large-scale test specimens, including CFST columns reinforced with steel bars or angle lattices and the control groups of steel and CFST columns, were tested under axial (Chen et al., 2017a; Xu et al., 2019) and eccentric tension (Chen et al., 2017b). The details for each test specimen are shown in Figure 7. All test specimens failed at the yielding of outer tube and cracking of inner concrete.

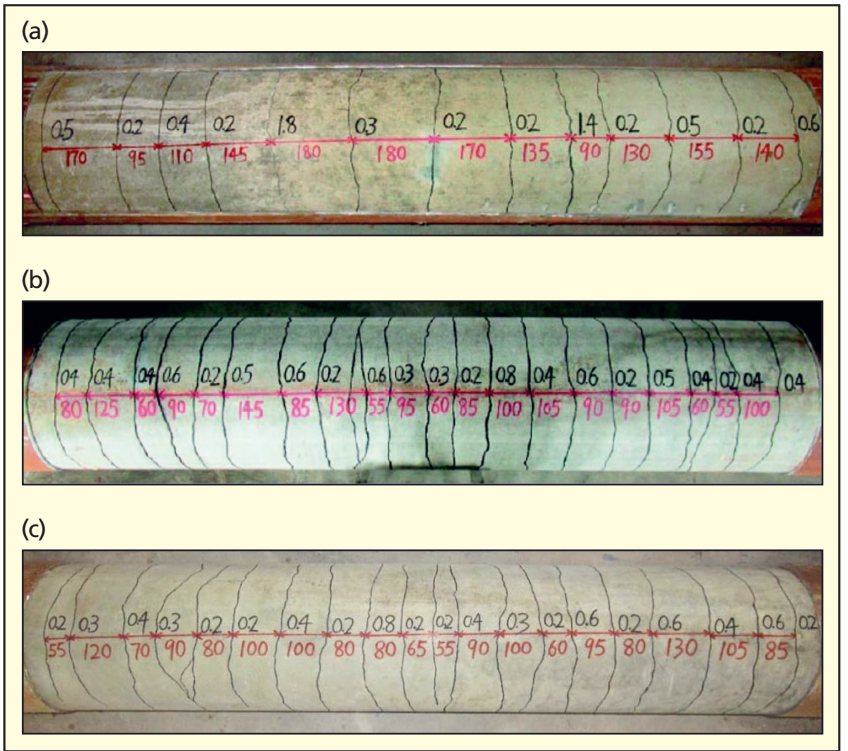

Figure 8. Cracks in concrete cores from CFST specimens under axial tension without (a) and with (b, c) encased angle lattice (Chen et al., 2017a, 2017b)

The crack patterns of inner concrete for the specimens under axial and eccentric loading, as shown in Figure 8, indicated that the maximum crack width and spacing developed in the inner concrete of encased angle CFST columns were significantly reduced compared to the CFST counterparts. The test results showed that the embedded reinforcement could work synergistically with the CFST columns and effectively contribute to the column strength through load transfer by the concrete. Therefore, the initial stiffness and tensile strength were significantly increased due to the presence of the angle and steel reinforcement.

The design equations and tension-moment relationship, considering composite actions among components, were proposed. The design equations for the encased angle CFST members under axial (Chen et al., 2017a; Xu et al., 2019) and eccentric tension (Chen et al., 2017b) are summarised in Equations 4-8. It should be noted that more experimental and numerical investigations were also needed to verify the proposed design equations and provide the safe, reliable and effective design framework to guide the practical design.

\subsubsection{Initial stiffness}

Axial tension, $(E A)_{\mathrm{AXT}}$

$$
\text { 4. }(E A)_{\mathrm{AXT}}=E_{\mathrm{so}}=A_{\mathrm{so}}+0 \cdot 1\left(E_{\mathrm{c}} A_{\mathrm{c}}+E_{\mathrm{si}} A_{\mathrm{si}}\right)
$$

Eccentric tension, $(E A)_{\mathrm{ECT}}$

5. $(E A)_{\mathrm{ECT}}=\left(1+\omega^{2}\right) \times(E A)_{\mathrm{AXT}}$

where AXT refers to axial tension loading and ECT refers to eccentric tension loading. 


\subsubsection{Design strength}

Axial tension, $F_{\mathrm{u}, \mathrm{AXT}}$

6. $\quad F_{\mathrm{u}, \mathrm{AXT}}=\beta_{\mathrm{so}} f_{\mathrm{yo}} A_{\mathrm{so}}+\beta_{\mathrm{si}} f_{\mathrm{yi}} A_{\mathrm{si}}$

Eccentric tension, $F_{\mathrm{u}, \mathrm{ECT}}$

7. $\left(\frac{F_{\mathrm{u}, \mathrm{ECT}}}{F_{\mathrm{u}, \mathrm{AXT}}}\right)^{2}+\left(\frac{e \times F_{\mathrm{u}, \mathrm{ECT}}}{M_{\mathrm{u}}}\right) \leq 1 \cdot 0$

where $M_{\mathrm{u}}$ is the flexural strength of reinforced CFST members, which can be calculated as follows

8. $M_{\mathrm{u}}=M_{\mathrm{sc}, \mathrm{u}}=M_{\mathrm{p}}$

9. $M_{\mathrm{sc}, \mathrm{u}}=\gamma_{\mathrm{m}} W_{\mathrm{sc}} f_{\mathrm{scy}}$

$\beta_{\mathrm{so}}$ and $\beta_{\mathrm{si}}$ are the stress coefficients of the tube and the angles, respectively, which can be calculated as follows

10. $\beta_{\mathrm{so}}=1 \cdot 1-0 \cdot 4 \alpha_{\mathrm{T}}$

11. $\beta_{\mathrm{si}}= \begin{cases}0 \cdot 85 & 0 \cdot 14 \leq \phi_{\mathrm{si}} \leq 0 \cdot 95 \\ \frac{0 \cdot 828}{\sqrt{\phi_{\mathrm{si}}}} & 0 \cdot 95 \leq \phi_{\mathrm{si}} \leq 100 \cdot 0\end{cases}$

where $\gamma_{\mathrm{m}}=1 \cdot 1+0 \cdot 48 \ln (\xi+0 \cdot 1) ; W_{\mathrm{sc}}=\pi D^{3} / 32 ; f_{\mathrm{scy}}=(1 \cdot 14+1 \cdot 02 \xi)$ $f_{\mathrm{ck}} ; \phi_{\mathrm{si}}=\left(A_{\mathrm{si}} /\left(C_{\mathrm{si}} \times L\right)\right) \times\left(\rho_{\mathrm{si}, \mathrm{T}} / \alpha_{\mathrm{T}}\right) ; \rho_{\mathrm{si}, \mathrm{T}}$ is the angle-tube ratio; $\rho_{\mathrm{si}, \mathrm{T}}=f_{\mathrm{yi}} A_{\mathrm{si}} / f_{\mathrm{yo}} A_{\mathrm{so}}$.

\subsection{Joints}

Three groups of large-scale CFST longitudinal gusset plate joints were tested under axial tension, eccentric tension and inplane bending, respectively (Xu et al., 2016a). Test specimens failed in tube wall punching shear, with the typical failure mode shown in Figure 8 . The deformation limit, 3\% of tube diameter, in the design guideline CIDECT-1 (Wardenier et al., 2008) for pure steel joints was found not to govern the ultimate state of the composite joints, which had been verified by both experimental (Xu et al., 2016a) and numerical (Xu et al., 2017a) investigations.

The inner concrete increased the radius stiffness of the chord member, thus mitigating the tube-wall flexibility. In the design specification of Eurocode 3 (BSI, 2005b), the design strength of hollow section joints was determined by the lower value between the plastification strength and punching shear strength (without concrete). However, these guidelines could fail to predict the failure mode accurately and underestimate the strengths of concrete-filled joints.

The fracture mechanism-based numerical analyses (Xu et al., 2107a) were performed to investigate the punching shear mechanism of the composite joints. Based on experimental, numerical and theoretical investigations, the design methodology and design equations were proposed as shown in Figure 9 and Table 1, respectively. They provided accurate and reliable predictions for composite joints under various loading conditions.
Experimental, numerical and theoretical investigations were conducted to derive the mechanical performance of CHS to CFST joints under tension and in-plane bending. In total, 24 large-scale joint specimens were tested (Chen et al., 2010; Xu et al., 2015a, 2017b), including T, Y, K and KT types of joints, under static and cyclic loadings of tension and in-plane bending.

The discrepancies between pure steel and CFST joints on both stress concentration factor distributions and maximum values were observed from tests (Chen et al., 2010; Xu et al., 2015b). The design recommendations (API, 2014; DNV, 2005; Wardenier et al., 2008) would give a higher stress concentration factor value, leading to conservative predictions on the fatigue life. The typical failure mode, as shown in Figure 9, was punching shear fracture of the tube wall near the weld toe.

The analogous investigation methodology in the plate joint investigation, as shown in Figure 9, was also adopted (Xu et al., 2015a, 2016b, 2017b) to obtain the capacity design equations for the CFST-CHS joints (Figure 10). The design equations (Xu et al., 2016b, 2017b) are summarised in Table 2.

\section{Conclusions}

The $380 \mathrm{~m}$ tall Zhoushan towers, like their $370 \mathrm{~m}$ tall predecessors, demonstrate successful practical application of innovative CFST members with encased angle lattices and corresponding joints.

The CFST members achieved and provided advantages in mechanical performance, manufacturability and constructability compared with hollow steel sections in the long-span electrical transmission towers.

The encased angle lattices worked effectively with the CFST member, provided a substantial complementary steel area, and significantly improved the strength of a thin-walled CFST member. Construction work also benefited from the encased lattices.

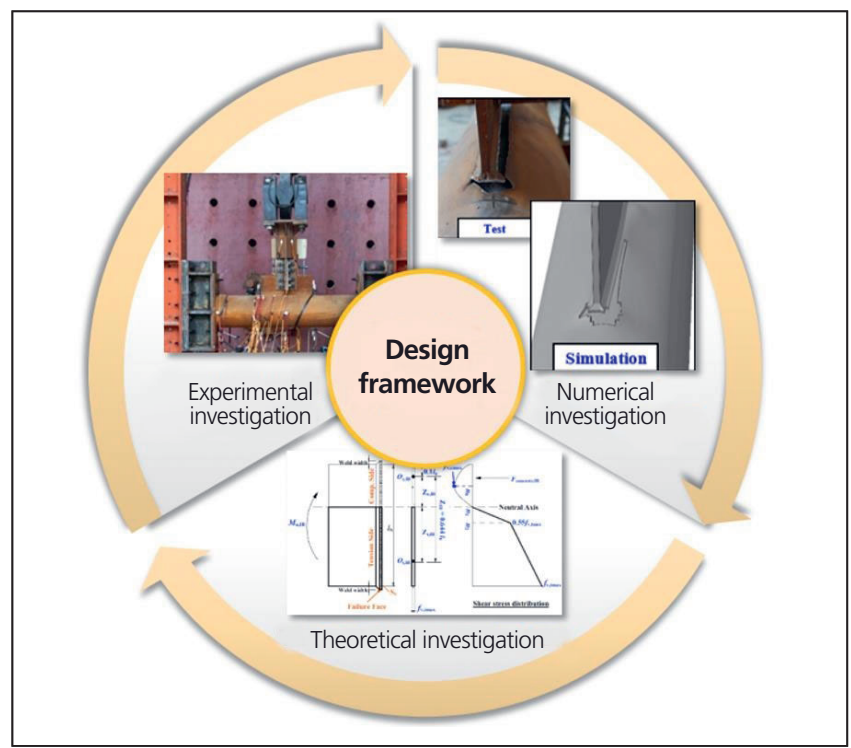

Figure 9. Schematic diagram of investigations on CFST-gusset plate connections 
Civil Engineering

Volume 172 Issue CE5
Innovative design of the world's tallest electrical transmission towers

$\mathrm{Xu}$, Chen, Guo and Ye

Table 1. Proposed design capacity of CFST-plate connections (Xu et al., 2017a)

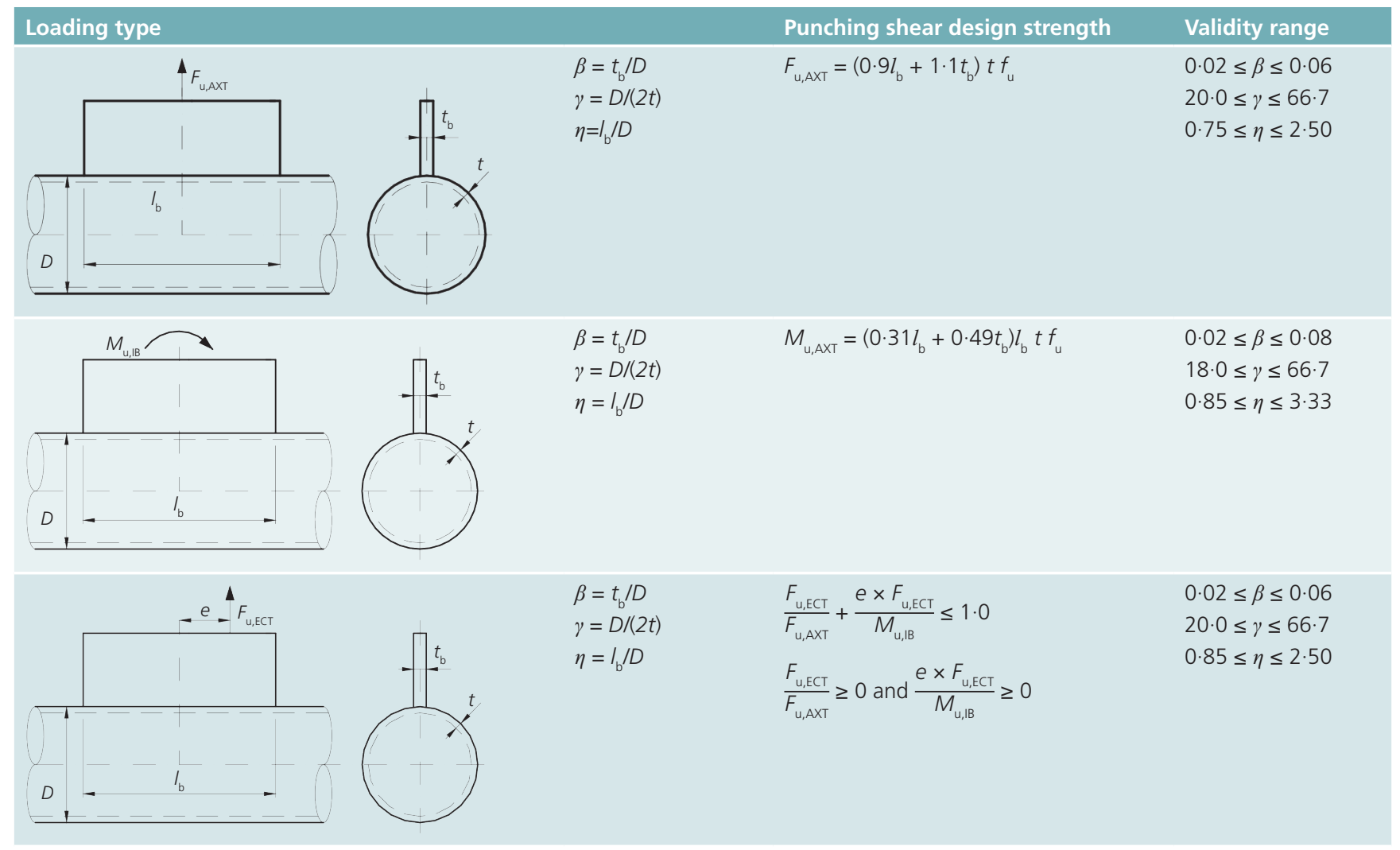

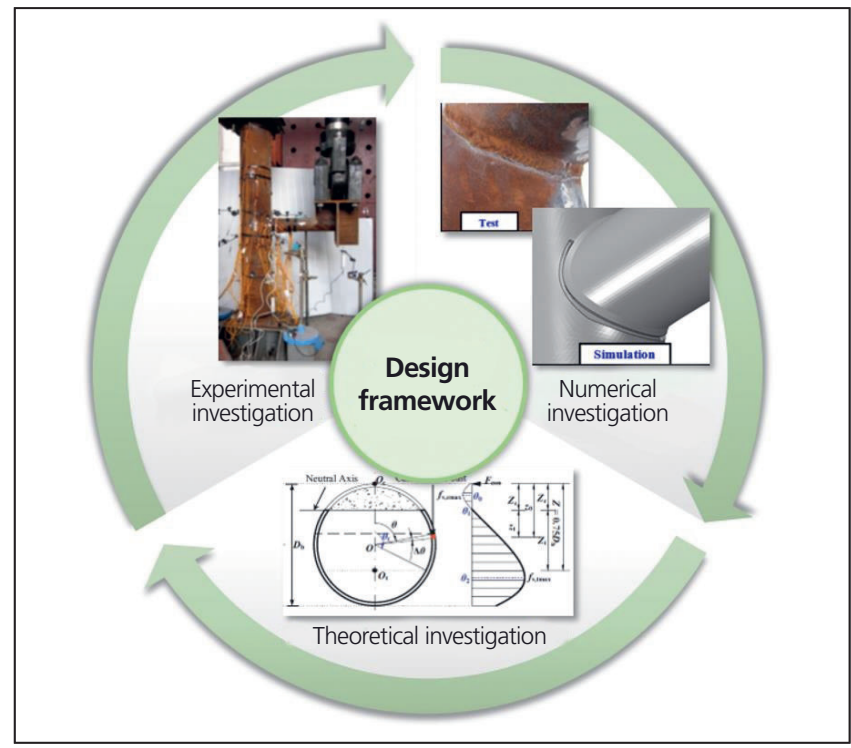

Figure 10. Schematic diagram of investigations on CFST-CHS connections

The composite joints and spherical joints provided excellent mechanical performance and good load-transfer mechanism within the connecting regions. Extensive investigations and close collaboration between industrial designers and university researchers were essential to establish the design framework and ensure successful design and construction.

All key techniques adopted in the structural design aimed to achieve safe, reliable and sustainable infrastructure. Moreover, these innovative techniques helped to save up to US\$5 million in constructing the transmission towers compared to a conventional pure steel design.

The techniques adopted at Zhoushan can improve the performance and constructability of future large-span electrical transmission towers worldwide.

\section{References}

AISC (American Institute of Steel Construction) (2010) ANSI/AISC 360-10: Specification for structural steel buildings. American Institute of Steel Construction, Chicago, IL, USA.

API (American Petroleum Institute) (2014) RP2A-WSD: Recommended practice for planning, designing and constructing fixed offshore platforms. API, Washington, DC, USA.

BSI (2005a) BS EN 1993-1-1:2005: Eurocode 3: Design of steel structures - part 1-1: General rules and rules for buildings. BSI, London, UK.

BSI (2005b) BS EN 1993-1-1:2005: Eurocode 3: Design of steel structures - part 1-8: Design of joints. BSI, London, UK.

Chen J, Chen J and Jin WL (2010) Experiment investigation of stress concentration factor of concrete-filled tubular T joints. Journal of Constructional Steel Research 66(12): 1510-1515.

Chen J, Wang J and Jin WL (2017a) Concrete-filled steel tubes with reinforcing bars or angles under axial tension. Journal of Constructional Steel Research 133: 374-382. 
Table 2. Proposed design capacity of CFST-CHS connections (Xu et al., 2016b, 2017b)

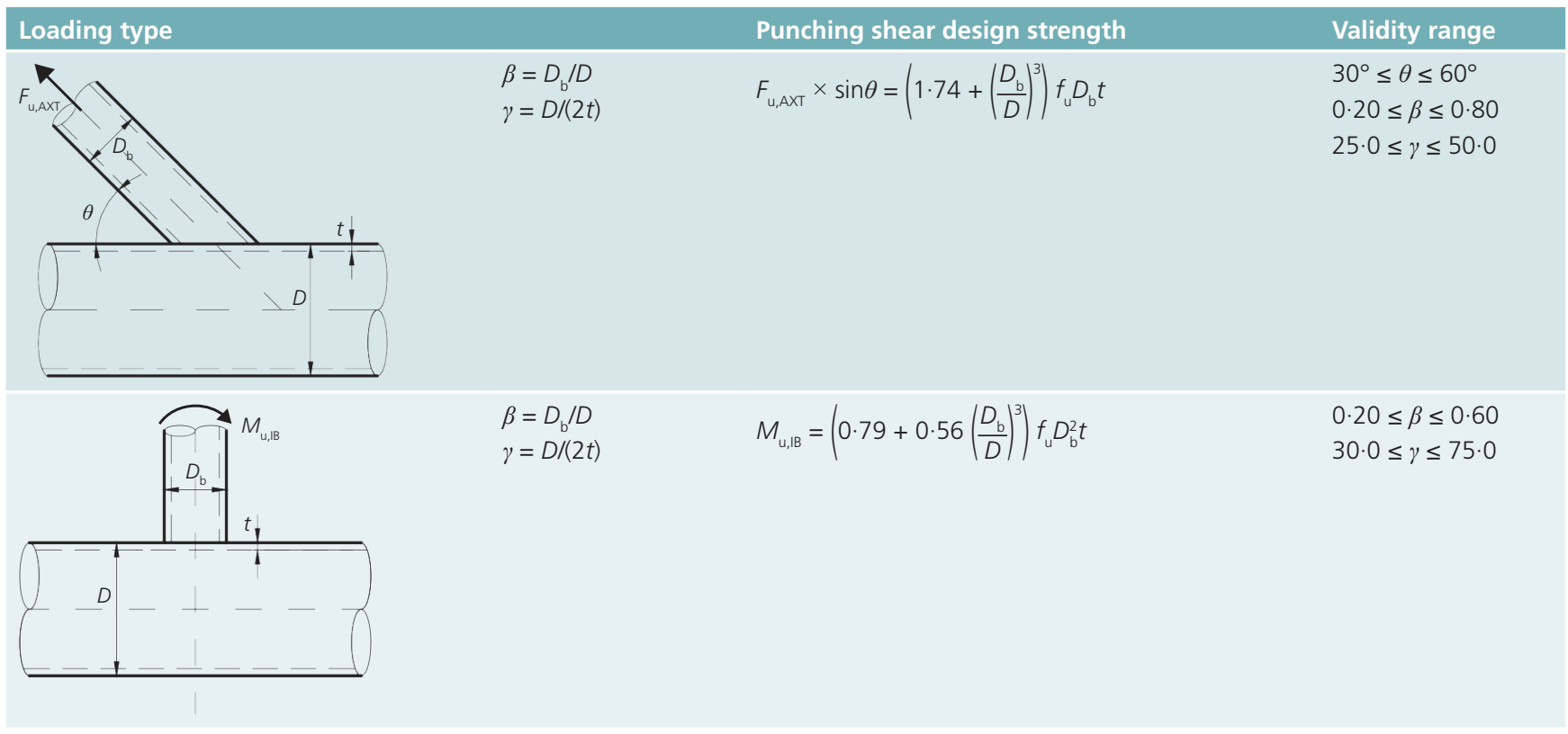

Chen J, Wang J and Li W (2017b) Experimental behaviour of reinforced concrete-filled steel tubes under eccentric tension. Journal of Constructional Steel Research 136: 91-100.

DNV (Det Norske Veritas) (2005) DNV recommended practice RP-C203: Fatigue strength analysis of offshore of steel structures. DNV, Oslo, Norway.

Han LH (2006) Further study on the flexural behaviour of concrete-filled steel tubes. Journal of Constructional Steel Research 62(6): 554-565.

Han LH, Li W and Bjorhovde R (2014) Developments and advanced applications of concrete-filled steel tubular (CFST) structures: members. Journal of Constructional Steel Research 100: 211-228.

Huang MF, Lou WJ and Yang L et al. (2012) Experimental and computational simulation for wind effects on the Zhoushan transmission towers. Structure and Infrastructure Engineering $\mathbf{8 ( 8 )}$ 781-799.

Nie JG, Wang Y and Fan J (2013) Experimental study on seismic behavior of concrete filled steel tube columns under pure torsion and compression-torsion cyclic load. Journal of Constructional Steel Research 79: 115-126.

Nie X, Wang H, Li S and Chen J (2018) Coupled bending-shear-torsion bearing capacity of concrete filled steel tube short columns. ThinWalled Structures 123: 305-316.

Perea T, Leon RT, Hajjar JF et al. (2013) Full-scale tests of slender concretefilled tubes: axial behavior. Journal of Structural Engineering 139(7) 1249-1262.

SAC (Standardization Administration of China) (2003a) GB 50017-2003: Specifications for the design of steel structures. China Building Industry Press, Beijing, China (in Chinese).

SAC (2003b) JGJ 61-2003: Technical specification for latticed shells. China Building Industry Press, Beijing, China (in Chinese).

Uy B (2001) Local and postlocal buckling of fabricated steel and composite cross sections. Journal of Structural Engineering 127(6) 666-677.

Wang YH, Wang W and Chen J (2018a) Seismic behavior of steel tube confined RC columns under compression-bending-torsion combined load. Journal of Constructional Steel Research 143(43): 83-96.

Wang YH, Lu GB and Zhou XH (2018b) Experimental study of the cyclic behavior of concrete-filled double skin steel tube columns subjected to pure torsion. Thin-Walled Structures 122(1): 425-438.
Wardenier J, Kurobane Y, Packer JA, van der Vegte GJ and Zhao XL (2008) Design Guide for Circular Hollow Section (CHS) Joints Under Predominantly Static Loading, 2nd edn. Comité International pour le Développement et l'Étude de la Construction Tubulaire, LSS Verlag, Germany.

Xu F, Chen J and Jin WL (2014) Experimental investigation of thin-walled concrete-filled steel tube columns with reinforced lattice angle. ThinWalled Structures 84: 59-67.

Xu F, Chen J and Jin WL (2015a) Experimental investigation and design of concrete-filled steel tubular CHS connections. Journal of Structural Engineering 141(2): 04014106

Xu F, Chen J and Jin WL (2015b) Experimental investigation of SCF distribution for thin-walled concrete-filled CHS joints under axial tension loading. Thin-Walled Structures 93: 149-157.

Xu F, Chen J and Jin WL (2016a) Experimental investigation of concretefilled steel tubular longitudinal gusset plate connections. Journal of Constructional Steel Research 124: 163-172.

Xu F, Chen J and Jin WL (2016b) Punching shear failure of concrete-filled steel tubular CHS connections. Journal of Constructional Steel Research 124: $113-121$

Xu F, Chen J and Chan TM (2017a) Numerical analysis and punching shear fracture based design of longitudinal plate to concrete-filled CHS connections. Construction and Building Materials 156: 91-106.

Xu F, Chen J and Chan TM (2017b) Mechanical behaviour of concretefilled CHS connections subjected to in-plane bending. Engineering Structures 148: 101-112.

Xu F, Chen J and Chan TM (2017c) Numerical investigation on compressive performance of CFST columns with encased built-up lattice-angles. Journal of Constructional Steel Research 137: 242-253.

Xu F, Wang J, Chen J and Wang YH (2019) Load-transfer mechanism in angle-encased CFST members under axial tension. Engineering Structures 178: 162-178.

\section{How can you contribute?}

If you would like to comment on this paper, please email up to 200 words to the editor at journals@ice.org.uk.

If you would like to write a paper of 2000 to 3500 words about your own experience in this or any related area of civil engineering, the editor will be happy to provide any help or advice you need. 